\title{
Mean effective volume of local anesthetics by nerve conduction technique
}

\author{
Junjie Luo", Guangyu Cai", Dandan Ling", Na Zhang, Xiaorui Chen, Xiaodan Cao, Bin Yu \\ Department of Anesthesiology, Shanghai Tongji Hospital, Tongji University School of Medicine, Shanghai 200065, China \\ Contributions: (I) Conception and design: B Yu, G Cai, D Ling; (II) Administrative support: B Yu; (III) Provision of study materials or patients: J Luo, \\ G Cai, D Ling, N Zhang, X Cao, X Chen; (IV) Collection and assembly of data: J Luo, G Cai, D Ling, N Zhang, X Cao, X Chen; (V) Data analysis \\ and interpretation: J Luo, G Cai, D Ling; (VI) Manuscript writing: All authors; (VII) Final approval of manuscript: All authors. \\ \#These authors contributed equally to the work. \\ Correspondence to: Bin Yu. Department of Anesthesiology, Shanghai Tongji Hospital, Tongji University School of Medicine, No.389, Xincun Road, \\ Putuo District, Shanghai 200065, China. Email: yubin@tongji.edu.cn.
}

Background: This study aimed to investigate whether nerve conduction could be used to objectively evaluate mean effective volume of $1.5 \%$ lidocaine after subparaneural or extraparaneural injection.

Methods: Twenty patients undergoing unilateral foot or ankle surgery were randomized into either subparaneural or extraparaneural injection group, and ultrasound-guided continuous popliteal sciatic nerve block was performed. The action potential amplitude of the distal gastrocnemius muscle was monitored. The time of anesthesia onset and dosage of lidocaine were recorded when amplitude declined to $0.5 \mathrm{mV}$. The operative analgesic effect, score of numeric rating scales, patient's satisfaction, and movement or sensation were recorded during or after surgery.

Results: Preoperative dose of local anesthetics $(10.7 \pm 1.6$ vs. $16.2 \pm 1.2 \mathrm{~mL})$ and the time of onset $(19.4 \pm 3.3$ vs. $30.4 \pm 2.5 \mathrm{~min})$ reduced significantly in the subparaneural group $(\mathrm{P}<0.05)$. The intra-operative analgesic effect $(1.2 \pm 0.422$ vs. $1.3 \pm 0.483)$ and the score of resting numeric rating scales $(0.6 \pm 1.0 v s .1 .9 \pm 2.1$ and $0.4 \pm 0.7$ vs. $1.2 \pm 1.1) 24$ and $48 \mathrm{~h}$ after surgery were comparable between groups, but the subparaneural group had markedly lower scores of activity numeric rating scales $(0.3 \pm 0.6$ vs. $2.1 \pm 2.0,0.7 \pm 1.2$ vs. $2.2 \pm 1.9$ and $0.5 \pm 0.8$ vs. $1.5 \pm 1.2)$ at 6,24 and $48 \mathrm{~h}$, and significantly higher satisfaction $(9.7 \pm 0.5$ vs. $8.8 \pm 0.8)(\mathrm{P}<0.05)$. There were no obvious symptoms of movement or sensation within 3 days in two groups.

Conclusions: The nerve conduction can be used to objectively evaluate the mean effective volume of $1.5 \%$ lidocaine in different injection groups, and subparaneural injection has more advantages as compared to extraparaneural injection for continuous popliteal sciatic nerve block.

Keywords: Nerve block; lidocaine; minimum effective volume; sciatic nerve; nerve conduction assessment

Submitted Sep 25, 2019. Accepted for publication Jan 10, 2020.

doi: $10.21037 /$ atm.2020.01.96

View this article at: http://dx.doi.org/10.21037/atm.2020.01.96

\section{Introduction}

The popularization of ultrasonic visualization has allowed extensive application of nerve block anesthesia in clinical practice. The multisite block is often needed for local anesthesia owing to the complexity of nerve innervation; however, excessive use of drugs has also drawn clinical attention, especially in critically ill elderly patients. Besides the toxicity to the cardiovascular system (1), local anesthetics may also exhibit chronic neurotoxicity $(2,3)$. Local anesthetics can act on neurosoma and nerve fibers, leading to cell membrane lysis, neural cell apoptosis, delayed axonal transport and marginal growth crown, as well as atrophy of growing nerve fibers. Moreover, the continuous nerve block with local anesthetics may cause significant relaxation and dissolution of surrounding skeletal muscles (4), as well 
as denaturation and karyopyknosis of the neural cells (5). Therefore, the minimum effective dose of local anesthetics is recommended in the clinical nerve blockage. Currently, the sequential method is often applied for the determination of median effective dose and concentration of local anesthetics in clinical practice. Clinically, the patients judge their pain with a specific subjective necessity, which is often prone to deviations, and not to mention that the operation is also complicated. The present study evaluated the effect of nerve block anesthesia and the accurate dosage of local anesthetic by nerve conduction technology. Ultrasound-guided popliteal sciatic nerve block has been widely used in foot and ankle surgery (6-10). Recent studies have shown that, compared with the extraparaneural injection, the subparaneural injection of local anesthetics can achieve a shorter onset time (11) and a higher success rate of block (12). However, no study has been conducted to evaluate the dose of local anesthetics for paraneural injection using nerve conduction study technology.

Therefore, this study aimed to investigate the accurate dose of local anesthetics by assessing the nerve conduction and evaluate the efficacy of nerve block anesthesia via two routes. Our study may provide evidence on the use of local anesthetics for nerve block in the clinical foot and ankle surgery.

\section{Methods}

\section{Ethics}

This study was approved by the Ethics Committee of Shanghai Tongji Hospital (No. 394) and registered in the Chinese Clinical Trial Registry (http://www.chictr.org.cn; registration No. ChiCTR-INR-17011708). All patients were informed about the procedures in detail before anesthesia, and signed informed consent was obtained before the study.

\section{Subject recruitment and screening criteria}

Inclusion criteria: Patients were aged 18-65 years with American Society Anesthesiologists (ASA) physical status scores of I-III, and cooperated with the anesthesiologists. The surgeries included internal fixation of fractures (external malleolus, metatarsus, and calcaneus), hallux valgus orthopedic surgery, and flat foot orthopedic surgery.

Exclusion criteria: severe heart or lung diseases, severe mental or nervous system disease; lesions in the lower limb muscles or nerve of the surgical side; diabetic neuropathy; allergy to local anesthetics; abnormalities in the physical examinations, including blood, urine, or fecal test; hepatitis A or B, acquired immune deficiency syndrome, tuberculosis, and other active infectious diseases; abnormal electrocardiogram (ECG), including atrioventricular block and bradycardia; skin infection at puncture site; preexisting chronic pain treatment or history of drug abuse; preoperative excessive emotional stress.

\section{Grouping}

A total of 20 subjects were randomized into two groups ( $\mathrm{n}=10$ per group). The local anesthetics were injected subparaneurally (S group) or extraparaneurally (E group).

\section{Anesthesia procedures}

In the operating room, venous access was established and the blood pressure, arterial oxygen saturation and ECG were monitored. Dexmedetomidine was administered as a $\mathrm{n}$ intravenous tranquilizer at a loading dose of $0.8 \mu \mathrm{g} / \mathrm{kg}$ over $10 \mathrm{~min}$, and then dexmedetomidine was maintained with a pump at a rate of $0.3 \mu \mathrm{g} \cdot \mathrm{kg}^{-1} \cdot \mathrm{h}^{-1}$.

Patients were asked to lay in a lateral position and the target popliteal fossa was exposed. The short axis of the ultrasonic probe (SONAS-Nerve, Sonosite Co., USA) was placed on the sciatic nerve branching. In the $\mathrm{S}$ group, a novel continuous nerve block cannula-over-needle (20G$1.1 \times 50 \mathrm{~mm}$, Henan Tuoren Co., China) was stabbed into the skin at an angle of $30^{\circ}-45^{\circ}$ towards the foot side below the probe. With the guidance of ultrasound, the tip of the needle was placed between the common peroneal nerve and the tibial nerve, close to the base. Saline (less than $0.5 \mathrm{~mL}$ ) was injected to track the tip. The needle tip reached the accurate position when saline spread under the paraneural sheath to surround the nerve without nerve swelling. Subsequently, the inner needle was pulled out and replaced with an annular tube fixed with a membrane if no blood was drawn out. In the E group, the ultrasonic probe was placed at the same site as in the $\mathrm{S}$ group, but the needle was pricked into the skin adjacent to the lateral margin of the sciatic nerve in the direction towards the head. With tip approaching the lateral margin of the sciatic nerve in the ultrasonoscopy, the right site of the needle tip was ensured using the same method. When the saline surrounded the sheath without swelling, the needle was pulled out and the tube was fixed. 


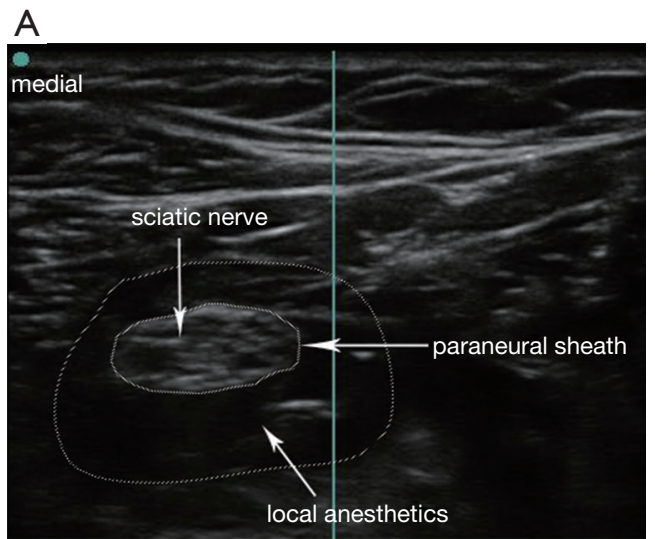

B

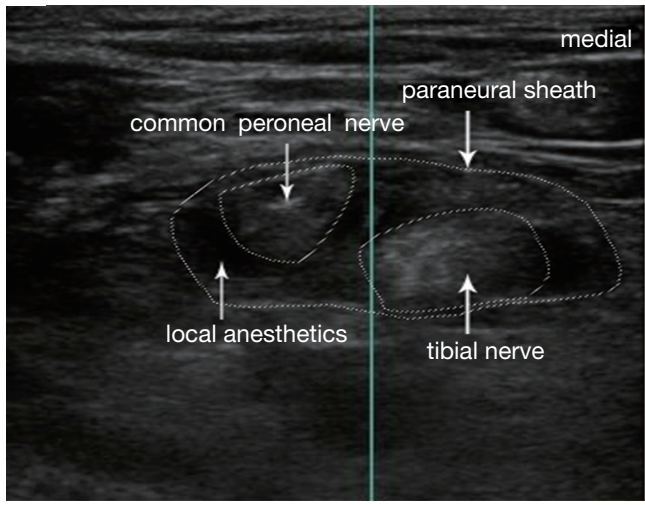

Figure 1 The ultrasound images after the local anesthetics injection. (A) Extraparaneural injection group, local anesthetics encapsulated the sciatic nerve outside the sheath; (B) subparaneural injection group, local anesthetics encapsulated the common peroneal nerve and the tibial nerve under the sheath.

The nerves of foot and ankle are mainly composed of sciatic nerve and femoral nerve. The motor and most of the sensation are related to the tibial nerve and peroneal nerve. Meanwhile, the sensation of medial ankle skin is under the control of saphenous nerve, a branch of the femoral nerve. The sciatic nerve block alone is enough for surgery except for the medial incision. Thus, femoral nerve block was performed in both groups to reduce the thigh tourniquet reaction and relieve the pain of medial ankle incision. Femoral nerve block was performed under the ultrasound-guidance. Using an in-plane technique, the skin was punctured with a block needle at the midpoint of the inguinal ligament, lateral to the artery. Then, $10 \mathrm{~mL}$ of $1.5 \%$ lidocaine was injected to the upper and lower femoral nerves independently for the block.

Subsequently, the nerve conduction assessment (NCA) was done. In brief, two needle stimulation electrodes were placed at $5 \mathrm{~cm}$ in the front of the block site. The needle tip was approximately $2 \mathrm{~mm}$ above the sciatic nerve under the ultrasound-guidance. The record electrodes were pasted on the tendon and the belly of the gastrocnemius. In addition, a reference electrode was placed between the stimulation electrode and record electrode. After the electrodes were connected to the nerve electrophysiological monitoring equipment (Z2J-AMP-NCC08, Nuocheng Co., China), the stimulation current was adjusted to record the maximum action potential amplitude of the muscle before the local anesthesia. When the local anesthetics was applied, the autonomic nerve was blocked first, followed by the sensory nerve fibers, and the motor nerve fibers and the propriocephalic sensory fibers with myelin sheaths were finally blocked. $5 \mathrm{~mL}$ of $1.5 \%$ lidocaine at a loading dose was injected for the nerve anesthesia. The additional $1.5 \%$ lidocaine was pumped at the rate of $30 \mathrm{~mL} / \mathrm{h}$ through the indwelling annular tube if the amplitude existed after $8 \mathrm{~min}$. NCA test was conducted once every $2 \mathrm{~min}$ until the recorded amplitude decreased to $0-0.5 \mathrm{mV}$. When the amplitude decreased to $0-0.5 \mathrm{mV}$, the complete block of motor nerve was defined. The sensory nerve had been already blocked before the motor nerve block. Therefore, the presence of motor nerve block was regarded as the endpoint of anaesthesia. Then the infusion of lidocaine was terminated, and the total time of lidocaine infusion and the dose of lidocaine were recorded. The locations of local anesthetics and nerve sheath are shown in Figure 1. The procedures for local anesthesia in the $\mathrm{S}$ and $\mathrm{E}$ groups are shown in Figure 2 and Figure 3, respectively.

The operation began immediately after the termination of drug infusion. The tourniquet was applied to the limb at the pressure of $250 \mathrm{mmHg}$. If the operation lasted for more than $90 \mathrm{~min}$ and patient could not tolerate the pain caused by tourniquet, the rate of dexmedetomidine infusion was increased and a small amount of propofol $(3-5 \mathrm{~mL})$ was added to relax the patient. A small dose of propofol could exert sedative and hypnotic effects, with little analgesic effect, either during or after the operation. An electronic analgesia pump (ZZB-II type, Nantong Aipu Co., China) connected to the indwelling nerve block annular tube was used for patient-controlled analgesia (PCA). The concentration of ropivacaine was $0.2 \%$, and the first dose 

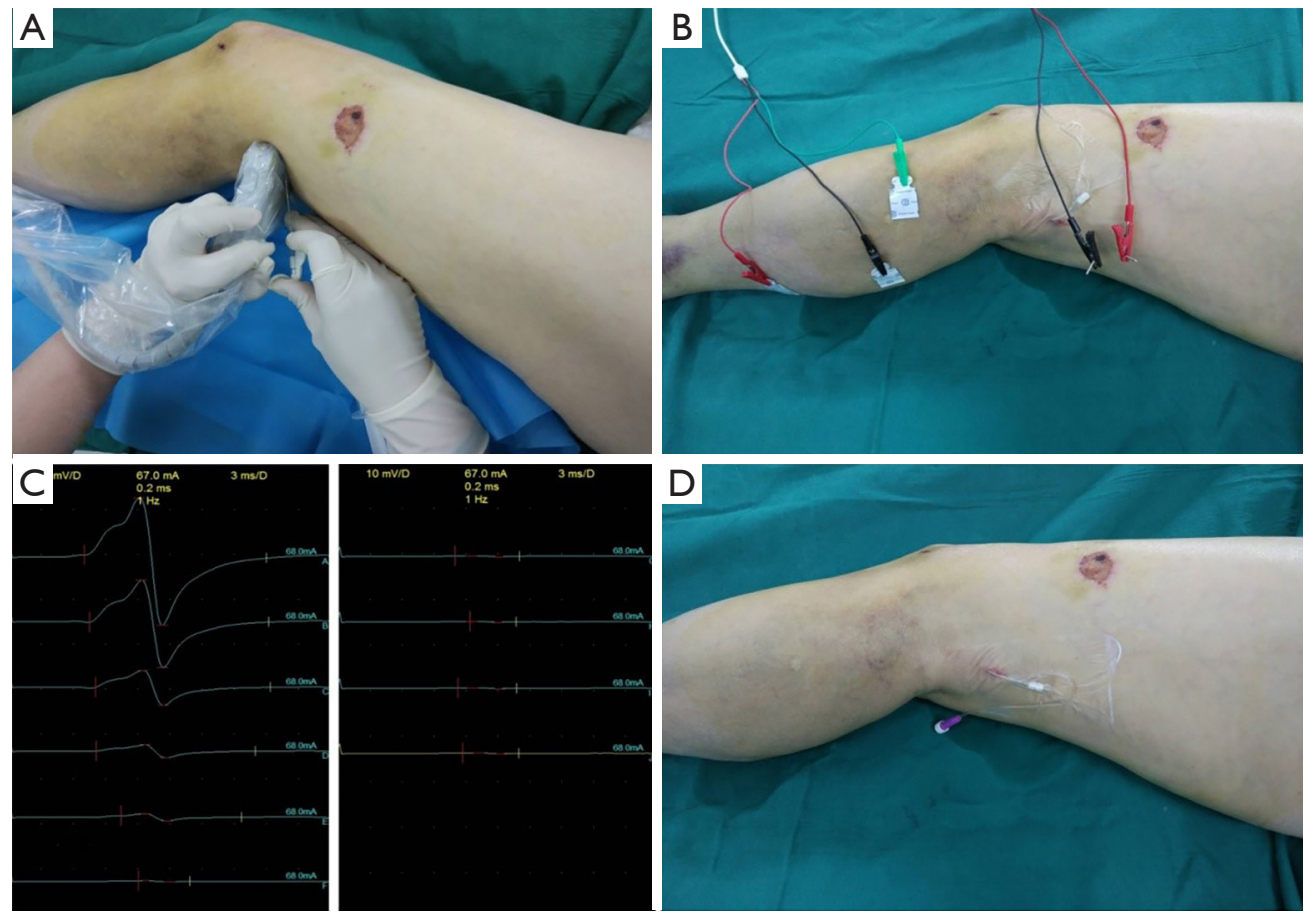

Figure 2 Subparaneural injection group. (A) Subparaneural injection with ultrasound guidance; (B) nerve conduction study; (C) variation trends of CMAP's amplitude; (D) indwelling and fixation of the annular tube.
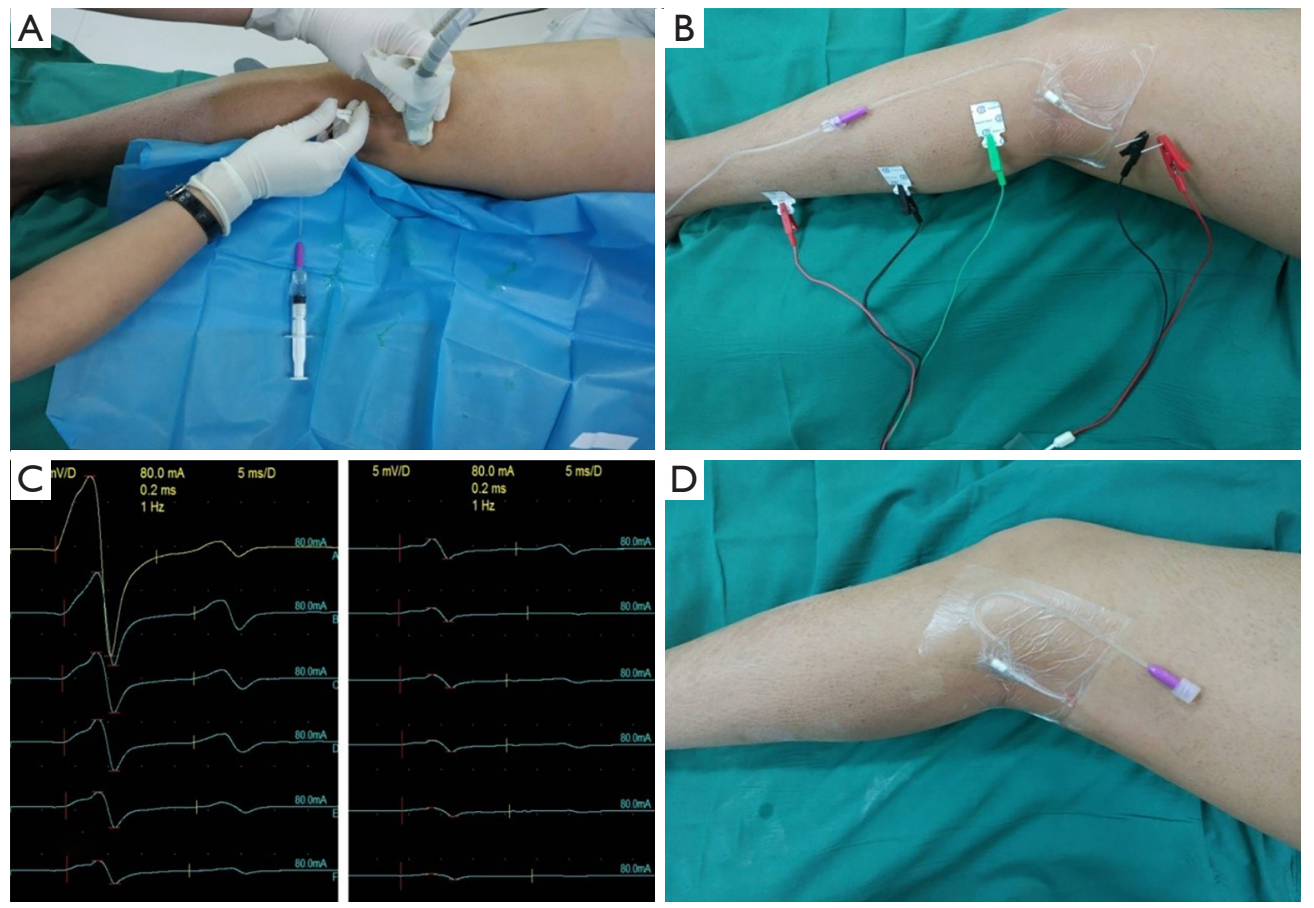

Figure 3 Extraparaneural injection group. (A) Extraparaneural injection with ultrasound guidance; (B) nerve conduction study; (C) variation trends of CMAP's amplitude; (D) indwelling and fixation of the annular tube. 
Table 1 Baseline characteristics of the patients

\begin{tabular}{lccc}
\hline & E group $(\mathrm{n}=10)$ & S group $(\mathrm{n}=10)$ & $\mathrm{P}$ \\
\hline Age (years) & $49.6 \pm 13.2$ & $53.3 \pm 8.8^{\#}$ & 0.472 \\
Male $(\%)$ & $6(60.0)$ & $5(50.0)^{\#}$ & 1.000 \\
BMl $\left(\mathrm{kg} / \mathrm{m}^{2}\right)$ & $26.2 \pm 2.6$ & $24.3 \pm 1.9^{\#}$ & 0.081 \\
ASA level & $1.3 \pm 0.5$ & $1.2 \pm 0.4^{\#}$ & 0.628 \\
Diameter of sciatic nerve $(\mathrm{cm})$ & $1.28 \pm 0.17$ & $1.22 \pm 0.14^{\#}$ & 0.404 \\
\hline
\end{tabular}

E group compared to the $S$ group, " , P>0.05 indicates no significant difference. BMI means body mass index, ASA means American Society Anesthesiologists.

was $0 \mathrm{~mL}$. The rate of ropivacaine administration was $5 \mathrm{~mL} / \mathrm{h}$. The maximum volume within $1 \mathrm{~h}$ was $25 \mathrm{~mL}$, and the postoperative analgesia lasted for $48 \mathrm{~h}$. If the catheter was blocked, the saline was injected or the position of the tube was adjusted. If both failed, the catheter was pulled out $0.5-1 \mathrm{~cm}$. Lastly, removing the indwelling nerve block annular tube and using other analgesic mode was the last option. Parecoxib sodium was administered when PCA was ineffective.

\section{Observations and scoring}

Primary observation: The total dose of local anesthetic used to depress the action potential amplitude of sciatic nerve to $0-0.5 \mathrm{mV}$ was recorded.

Secondary observation: The diameter of sciatic nerve bifurcation, the time to complete block under NCA, the operation time, the efficacy of anesthesia, the score of activity numeric rating scales (NRS) 6, 24, and $48 \mathrm{~h}$ after surgery, and the incidence of movement or sensation abnormality at 3 days after surgery were recorded. The Visual Analogue Scale (VAS) was use to assess the patients' satisfaction with 0 reflecting the least satisfaction and 10 the most satisfaction. Patients filled the scale according to their subjective feeling on the third day after surgery.

Numerical rating pain scale ( $0-10$ points): 0 , none; $1-3$, mild pain (unaffected sleep); 4-6, moderate pain; 7-9, severe pain (unable to sleep or wake up from pain); 10, sharp pain. The level of nerve block (level 1-4) was designated as follows: level 1, perfect nerve block, no pain, complete muscle relaxation and smooth surgery; level 2: imperfect nerve block, incomplete muscle relaxation, moderate pain; level 3 , imperfect nerve block, considerable pain, weak muscle relaxation, patients' groaning, dysphoria, and requirement of auxiliary medicine for operation; level 4: failure of anesthesia and applying alternative anesthetic method.

\section{Statistical analysis}

The statistical analyses were performed using the SPSS version 20.0 (International Business Machines, Armonk, NY, USA). The quantitative data are expressed as means \pm standard deviation (SD) unless otherwise specified. The continuous variables were compared using the independent $t$-test, while the categorical variables using the Pearson's Chi-square test or Fisher's exact test. A value of two-sided $\mathrm{P}<0.05$ was considered statistically significant.

\section{Results}

\section{Baseline characteristics of patients included}

The tolerance to anesthesia may be influenced by the baseline characteristics (13-15), and thus these were examined in the present study. The baseline characteristics included age, gender, body mass index, and ASA level. Results showed no significant differences in the baseline characteristics between two groups. It has been reported that the nerve's diameter also affects the spreading speed and efficacy of local anesthetics. In the present study, the diameter of popliteal sciatic nerve bifurcation $(1.22 \pm 0.14 v s$. $1.28 \pm 0.17 \mathrm{~cm})(\mathrm{P}=0.404)$ was similar between two groups as assessed by ultrasound (Table 1).

\section{Dose of local anesthetics and time to sciatic nerve block}

The nerve conduction was employed for the determination of total dose of local anesthetics and the time to nerve block. First, $5 \mathrm{~mL}$ of $1.5 \%$ lidocaine at a loading dose was injected, and then it was continually pumped until the action potential amplitude of the muscle declined to $0-0.5 \mathrm{mV}$. Results 
Table 2 Dosage and time of local anesthetics for blocking sciatic nerve

\begin{tabular}{lccc} 
& E group $(\mathrm{n}=10)$ & S group $(\mathrm{n}=10)$ & $\mathrm{P}$ \\
\hline Dosage of LA $(\mathrm{mL})$ & $16.2 \pm 1.2$ & $10.7 \pm 1.6^{*}$ & 0.000 \\
Time for block $(\mathrm{min})$ & $30.4 \pm 2.5$ & $19.4 \pm 3.3^{*}$ & 0.000 \\
\hline
\end{tabular}

E group compared to the $\mathrm{S}$ group, ${ }^{*}, \mathrm{P}<0.05$ indicates a significant difference. LA means local anesthetic.

Table 3 Intraoperative conditions and postoperative satisfaction of patients

\begin{tabular}{lcc}
\hline & E group $(\mathrm{n}=10)$ & $\mathrm{S}$ group $(\mathrm{n}=10)$ \\
\hline Patient with level 1 block effect (\%) & $7(70.0)$ & $8(80.0)$ \\
Patient with level 2 block effect (\%) & $3(30.0)$ & $0(0)$ \\
Patient with level 3 block effect (\%) & $0(0)$ & $0(0)$ \\
Patient with level 4 block effect (\%) & $0(0)$ & $1.20 \pm 0.422^{\#}$ \\
Anesthetic effect & $1.30 \pm 0.483$ & $90.6 \pm 12.7^{\#}$ \\
Surgery duration (min) & $101.0 \pm 12.5$ & $0(0)$ \\
Paresthesia (\%) & $0(0)$ & $0(0)$ \\
Motion abnormality (\%) & $0(0)$ & $9.7 \pm 0.5^{\star}$ \\
Patient satisfaction & $8.8 \pm 0.8$ & 0.028 \\
\hline
\end{tabular}

E group compared to the $\mathrm{S}$ group, ${ }^{*}, \mathrm{P}>0.05$ indicated no significant difference; ${ }^{*}, \mathrm{P}<0.05$ indicates a significant difference.

Table 4 Postoperative NRS score

\begin{tabular}{|c|c|c|c|c|c|c|c|c|c|}
\hline & \multicolumn{2}{|c|}{$6 \mathrm{~h}$} & $\mathrm{P}$ & \multicolumn{2}{|c|}{$24 \mathrm{~h}$} & $\mathrm{P}$ & \multicolumn{2}{|c|}{$48 \mathrm{~h}$} & $\mathrm{P}$ \\
\hline Resting NRS score & $1.9 \pm 2.1^{*}$ & $0.2 \pm 0.4$ & 0.024 & $1.9 \pm 2.1$ & $0.6 \pm 1.0$ & 0.090 & $1.2 \pm 1.1$ & $0.4 \pm 0.7$ & 0.074 \\
\hline Activity NRS score & $2.1 \pm 2.0^{*}$ & $0.3 \pm 0.6$ & 0.016 & $2.2 \pm 1.9^{\star}$ & $0.7 \pm 1.2$ & 0.045 & $1.5 \pm 1.2^{*}$ & $0.5 \pm 0.8$ & 0.043 \\
\hline
\end{tabular}

E group compared to the $\mathrm{S}$ group, ${ }^{*}, \mathrm{P}<0.05$ indicates a significant difference, NRS means numeric rating scales.

showed the dose of preoperative local anesthetic $(10.7 \pm 1.6$ vs. $16.2 \pm 1.2 \mathrm{~mL})(\mathrm{P}=0.000)$ and the time to complete block $(19.4 \pm 3.3$ vs. $30.4 \pm 2.5 \mathrm{~min})(\mathrm{P}=0.000)$ significantly reduced in the $\mathrm{S}$ group as compared to $\mathrm{E}$ group (Table 2).

\section{Intraoperative findings and postoperative satisfaction}

To evaluate anesthetic effect, the intraoperative findings were compared between two groups. All patients underwent surgery successfully with intravenous administration of dexmedetomidine. According to the level of nerve block, there were 7 patients with level 1 and 3 patients with level 2 in the E group, and there were 8 patients with level 1 and 2 patients with level 2 in the $\mathrm{S}$ group. The mean anesthetic effect $(1.2 \pm 0.422$ vs. $1.3 \pm 0.483)(\mathrm{P}=0.628)$ and the operation time
$(90.6 \pm 12.7$ vs. $101.0 \pm 12.5 \mathrm{~min})(\mathrm{P}=0.082)$ were comparable between two groups. Paresthesia and motion abnormality were not noted in the first 3 days after surgery. The patients' satisfaction scores were significantly higher in the $\mathrm{S}$ group than in the $\mathrm{E}$ group $(9.7 \pm 0.5$ vs. $8.8 \pm 0.8)(\mathrm{P}=0.006)$ (Table 3).

\section{Postoperative NRS score}

No significant differences were observed in the score of resting NRS between two groups (24 h: $0.6 \pm 1.0$ vs. 1.9 2.1; 48 h: $0.4 \pm 0.7$ vs. $1.2 \pm 1.1)(\mathrm{P}>0.05)$ after surgery. However, the score of active NRS in the $\mathrm{S}$ group was significantly lower than in the E group ( $6 \mathrm{~h}: 0.3 \pm 0.6$ vs. $2.1 \pm 2.0 ; 24 \mathrm{~h}$ : $0.7 \pm 1.2$ vs. $2.2 \pm 1.9 ; 48$ h: $0.5 \pm 0.8$ vs. $1.5 \pm 1.2)(\mathrm{P}<0.05)$ after surgery (Table 4). 


\section{Discussion}

Increasing studies on general anesthesia have identified the side effects of anesthetics. Both inhalational and intravenous anesthetics have shown to be neurotoxic $(2,3,16,17)$. A variety of retrospective studies have suggested that anesthesia is related to the post-operative cognitive dysfunction (POCD) in the elderly $(18,19)$. In addition, anesthesia may also affect teenagers after multiple exposures. A population-based birth cohort study reports that children receiving anesthesia more than 2 times have a higher risk for learning disability as compared to those without anesthetic exposure, and the risk is positively related to the cumulative duration of anesthesia (20). Recently, nerve block anesthesia gradually shows advantages in clinical practice. The nerve block has been demonstrated to decrease the adverse stress reaction induced by surgery or pain and has less influence on the function of other systems. In addition, nerve block is also related to the shorter hospital stay and lower medical cost as compared to other anesthesia methods (21).

Recent improvements in the neural location with ultrasound visualization and sedation with intravenous dexmedetomidine (22) have promoted the use of nerve block in clinical practice. However, more than one nerve often needs to be blocked in the target region and local anesthetics are susceptible to overdose, potentially leading to a toxic reaction, especially in the severely ill elderly patients. Therefore, the mean effective volume (MEV) and minimum effective anesthetics concentration (MEAC) are recommended in clinical practice. The sequential method is preferred for determining the $\mathrm{MEV}$ and MEAC in a clinical situation $(23,24)$; however, the determination of $M E V$ and MEAC is usually affected by the complicated operation and subjectiveness of reported pain. The present study determined the dose of local anesthetics in nerve block by NCA.

The NCA is often used for the diagnosis of peripheral nerve diseases and may reflect the functional state of the medullary motor nerve, the neuromuscular junction and the muscle fibers (25). Generally, after an electrical stimulation on the nerve trunk, the potential produced by the nerve impulse is recorded from the effector and termed as the compound muscle action potential (CMAP). CMAP represents activation of muscle fibers, which are innervated by the stimulated axons. The amplitude will decrease if the stimulation electrode and muscle are blocked, and it will disappear if complete block is achieved (no nervous reaction and a majority of the axons fail to conduct the impulse through the block point). The effect of local anesthetics is influenced by the relative mass of nerves (as opposed to the mass of tissues surrounding the nerves) and the perineurium forming a barrier for drug diffusion. The closer the nerve to the spinal cord, the higher the relative mass is. For example, the ratio of stromal and connective tissues to neural tissue is approximately $1: 1$ in the proximal sciatic nerve and 2:1 in the distal one (26). Therefore, a comparatively higher drug concentration is required as the relatively higher mass of nerve (27). In this study, the sciatic nerve is composed of motor and sensory nerve fibers. Since the sensory fiber is thin and can be blocked with the local anesthetic at a low concentration, and a relaxed muscle is necessary. In the present study, $1.5 \%$ lidocaine was used to block both motor and sensory nerves. The local anesthetics can diffuse through the non-neural and neural tissues with a delayed onset of block. Thus, $5 \mathrm{~mL}$ of lidocaine was injected in advance to achieve the optimal anesthetic effect within $8 \mathrm{~min}$, followed by pumping of the drug through the cannula tube. The electric stimulus was administered to the sciatic nerve with a short break, and the distal CMAP was recorded with the increase in the dose of lidocaine. When the amplitude decreased to $0-0.5 \mathrm{mV}$, injection was terminated. This time point and dose were selected for the complete block of the sciatic nerve. Because the motor nerve has a higher amplitude and it is easy to operate and more sensitive as compared to the sensory nerve. This was monitored by NCA, which indicated the effect of nerve block rather accurately and objectively, as it is independent on the loss of analgesia or motor function in the blocking region. However, the undesirable feeling was induced by the electric stimulation current, and thus dexmedetomidine was administered for sedation and analgesia, thereby increasing the patient's tolerance to the electric stimulation and anesthesia.

The injection of local anesthetics under or over popliteal sciatic paraneural sheath has a satisfactory efficacy in clinical practice, approving that NCA can efficiently determine the $\mathrm{MEV}$ of local anesthetics. It also provides a reference for investigation of MEV of unit area, combining the nerve's sectional area measured by ultrasound, which is helpful for the establishment of regional block quantization model. Furthermore, in the present study, the paraneural use of local anesthetic required lower dose, functioned more rapidly, led to enhanced operative activity, and achieved better analgesic effect and higher patient satisfaction as compared to extraparaneural injection. These features may be related to the perineurium mediated block of the local anesthetics diffusion, requirement of additional local 
anesthetics and prolonged diffusion time as shown in previous studies.

There are several limitations in the present study. The sample size is small in this study. Although no neural complications were observed, a more accurate information may be obtained if the sample size is bigger or duration of follow-up is longer.

\section{Conclusions}

The data presented in this article, indicates nerve conduction can be used to objectively evaluate the mean effective volume of $1.5 \%$ lidocaine in different injection groups, and subparaneural injection has more advantages as compared to extraparaneural injection for continuous popliteal sciatic nerve block. Further studies should be conducted to assess the long-term influence through this combined technique.

\section{Acknowledgments}

Funding: This study was funded by the Science and Technology Commission Shanghai Municipality project (No. 18441905700) and Shanghai Hospital Development Center project (No. 16CR3004A).

\section{Footnote}

Conflicts of Interest: The authors have no conflicts of interest to declare.

Ethical Statement: The authors are accountable for all aspects of the work in ensuring that questions related to the accuracy or integrity of any part of the work are appropriately investigated and resolved. This study was approved by the Ethics Committee of Shanghai Tongji Hospital (No. 394) and registered in the Chinese Clinical Trial Registry (http://www.chictr.org.cn; registration No. ChiCTR-INR-17011708). All patients were informed about the procedures in detail before anesthesia, and signed informed consent was obtained before the study.

Open Access Statement: This is an Open Access article distributed in accordance with the Creative Commons Attribution-NonCommercial-NoDerivs 4.0 International License (CC BY-NC-ND 4.0), which permits the noncommercial replication and distribution of the article with the strict proviso that no changes or edits are made and the original work is properly cited (including links to both the formal publication through the relevant DOI and the license). See: https://creativecommons.org/licenses/by-nc-nd/4.0/.

\section{References}

1. Brambrink AM, Orfanakis A, Kirsch JR. Anesthetic neurotoxicity. Anesthesiol Clin 2012;30:207-28.

2. Mete M, Aydemir I, Tuglu IM, et al. Neurotoxic effects of local anesthetics on the mouse neuroblastoma NB2a cell line. Biotech Histochem 2015;90:216-22.

3. Verlinde M, Hollmann MW, Stevens MF, et al. Local Anesthetic-Induced Neurotoxicity. Int J Mol Sci 2016;17:339.

4. Zink W, Seif C, Bohl JR, et al. The acute myotoxic effects of bupivacaine and ropivacaine after continuous peripheral nerve blockades. Anesth Analg 2003;97:1173-9, table of contents.

5. Zhou Y, He M, Zou T, et al. Morphological changes in the sciatic nerve, skeletal muscle, heart and brain of rabbits receiving continuous sciatic nerve block with $0.2 \%$ ropivacaine. Int J Clin Exp Pathol 2015;8:13911-20.

6. He M, Ling DD, Cai GY, et al. Two different placement paths in popliteal fossa with a novel nerve block needle for postoperative analgesia after foot and ankle surgery. Minerva Anestesiol 2018;84:582-9.

7. Choquet O, Noble GB, Abbal B, et al. Subparaneural versus circumferential extraneural injection at the bifurcation level in ultrasound-guided popliteal sciatic nerve blocks: a prospective, randomized, double-blind study. Reg Anesth Pain Med 2014;39:306-11.

8. Tiyaprasertkul W, Bernucci F, Gonzalez AP, et al. A Randomized Comparison Between Single- and TripleInjection Subparaneural Popliteal Sciatic Nerve Block. Reg Anesth Pain Med 2015;40:315-20.

9. Xu HQ, Zhang ZJ, Jia R, et al. Clinical observation of ultrasound guided popliteal sciatic nerve combined saphenous nerve block for hallux valgus patients with metatarsophalangeal joint dislocation. Zhongguo Gu Shang 2018;31:907-11.

10. Arjun BK, Prijith RS, Sreeraghu GM, et al. Ultrasoundguided popliteal sciatic and adductor canal block for below-knee surgeries in high-risk patients. Indian J Anaesth 2019;63:635-9.

11. Missair A, Weisman RS, Suarez MR, et al. A 3-dimensional ultrasound study of local anesthetic spread during lateral popliteal nerve block: what is the ideal end point for needle tip position? Reg Anesth Pain Med 2012;37:627-32. 
12. Perlas A, Wong P, Abdallah F, et al. Ultrasound-guided popliteal block through a common paraneural sheath versus conventional injection: a prospective, randomized, double-blind study. Reg Anesth Pain Med 2013;38:218-25.

13. Buchanan FF, Myles PS, Cicuttini F. Effect of patient sex on general anaesthesia and recovery. Br J Anaesth 2011;106:832-9.

14. Mavridou P, Dimitriou V, Manataki A, et al. Patient's anxiety and fear of anesthesia: effect of gender, age, education, and previous experience of anesthesia. A survey of 400 patients. J Anesth 2013;27:104-8.

15. Conti D, Ballo P, Boccalini R, et al. The effect of patient sex on the incidence of early adverse effects in a population of elderly patients. Anaesth Intensive Care 2014;42:455-9.

16. Vlisides $P, X i e$ Z. Neurotoxicity of general anesthetics: an update. Curr Pharm Des 2012;18:6232-40.

17. Vutskits L, Davidson A. Update on developmental anesthesia neurotoxicity. Curr Opin Anaesthesiol 2017;30:337-42.

18. Needham MJ, Webb CE, Bryden DC. Postoperative cognitive dysfunction and dementia: what we need to know and do. Br J Anaesth 2017;119:i115-25.

19. Jungwirth B, Zieglgansberger W, Kochs E, et al. Anesthesia and postoperative cognitive dysfunction (POCD). Mini Rev Med Chem 2009;9:1568-79.

20. Wilder RT, Flick RP, Sprung J, et al. Early exposure to anesthesia and learning disabilities in a population-based

Cite this article as: Luo J, Cai G, Ling D, Zhang N, Chen X, Cao X, Yu B. Mean effective volume of local anesthetics by nerve conduction technique. Ann Transl Med 2020;8(5):174. doi: 10.21037/atm.2020.01.96 birth cohort. Anesthesiology 2009;110:796-804.

21. Guay J, Johnson RL, Kopp S. Nerve blocks or no nerve blocks for pain control after elective hip replacement (arthroplasty) surgery in adults. Cochrane Database Syst Rev 2017;10:CD011608.

22. Bharti N, Sardana DK, Bala I. The Analgesic Efficacy of Dexmedetomidine as an Adjunct to Local Anesthetics in Supraclavicular Brachial Plexus Block: A Randomized Controlled Trial. Anesth Analg 2015;121:1655-60.

23. Sotthisopha T, Elgueta MF, Samerchua A, et al. Minimum Effective Volume of Lidocaine for UltrasoundGuided Costoclavicular Block. Reg Anesth Pain Med 2017;42:571-4.

24. Cappelleri G, Ambrosoli AL, Gemma M, et al. Intraneural Ultrasound-guided Sciatic Nerve Block: Minimum Effective Volume and Electrophysiologic Effects. Anesthesiology 2018;129:241-8.

25. Johnsen B, Fuglsang-Frederiksen A. Electrodiagnosis of polyneuropathy. Neurophysiol Clin 2000;30:339-51.

26. Moayeri N, Bigeleisen PE, Groen GJ. Quantitative architecture of the brachial plexus and surrounding compartments, and their possible significance for plexus blocks. Anesthesiology 2008;108:299-304.

27. Vadhanan P, Tripaty DK, Adinarayanan S. Physiological and pharmacologic aspects of peripheral nerve blocks. J Anaesthesiol Clin Pharmacol 2015;31:384-93. 